\title{
DEMOCRATIZAR LOS DIÁLOGOS ENTRE UNIVERSIDAD Y TERRITORIOPARA LA CONSTRUCCIÓN DE CONOCIMIENTOS
}

\section{[ CECILIA CERASO ]}

Docente e investigadora de la Facultad de periodismo y comunicación de la Universidad Nacional de La Plata (UNPL).

Magister en comunicación social de la UNPL. Directora de la Maestría PLANGESCO y del Centro de investigación en comunicación y políticas públicas de la UNPL.

negriceraso司yahoo.com.ar

Recibido: marzo 12 de 2014 Aceptado: mayo 5 de 2014 
Este trabajo es una investigación epistemológica y metodológica sobre los fundamentos que sustentan nuestras prácticas. La catástrofe de la inundación de la ciudad de La Plata, en abril de 2013, expuso una relación compleja entre el Estado, las políticas públicas y las organizaciones territoriales, y evidenció un agotamiento del modelo de la modernidad para la resolución de problemáticas socio-ambientales. A partir de nuevas propuestas epistemológicas y desde metodologías basadas en la complejidad, la universidad ha re-pensado otros modos de relación con el territorio, con proyectos interdisciplinarios, abordajes y prácticas integrales, y recuperaciones y co-construcciones de saberes con todos los actores implicados en la problemática.

Palabras clave: Mapas socio-comunicacionales, políticas públicas, universidad-territorio, trabajo en red, prácticas sociales.

\section{DEMOCRATIZING THE DIALOGUES BETWEEN UNIVERSITY AND TERRITORY FOR KNOWLEDGES CONSTRUCTION ABSTRACT}

This work is an epistemological and methodological research about the basics that support our practices. The catastrophe of the flood in La Plata city, on April 2013, exposed a complex relationship among State, public policies and territorial organizations, and made clear an exhaustion of the modernity model for the resolution of socio-environmental problems. From new epistemological proposals and methodologies based on complexity, university has re-thought other ways of relationship to the territory, with interdisciplinary projects, integral and practical approximations, and knowledges recuperations and co-constructions with the actors implied in the problematic.

Keywords: Socio-communicational maps, public policies, university-territory, network, social practices.

\section{INTRODUCCIÓN}

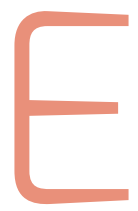

12 de abril de 2013, la ciudad de La Plata sufrió la peor inundación de su historia. La catástrofe puso en evidencia la compleja relación existente entre el Estado, las políticas públicas y las organizaciones territoriales. Desde lo acontecido, las organizaciones sociales y políticas tuvieron que reacomodar sus finalidades en pro de acompañar a los damnificados en el proceso de reconstrucción del territorio y de reflexión sobre lo ocurrido.

La Facultad de Periodismo y Comunicación Social (FPyCS), como una institución educativa sensible al territorio donde está inserta, tuvo y tiene una importante participación en ese proceso.

Esta sensibilidad territorial es posible porque desde hace muchos años trabaja en diferentes proyectos de docencia, investigación, extensión y transferencia que la vinculan con las organizaciones del territorio. La convocatoria a todas las Facultades de la Universidad de La Plata para realizar proyectos de desarrollo tecnológico y social, Proyectos de Investigación Orientados (PIO) a hacer diagnósticos del territorio afectado por la emergencia hídrica y realizar actividades de diálogos de saberes, extensión y transferencia con los habitantes la ciudad, nos dio la oportunidad histórica de integrarnos en equipos con investigadores de varias Facultades, poner objetivos en común, aprender y compartir las diferentes perspectivas que cada ciencia y unidad académica tienen acerca de éste fenómeno. En este contexto, desde la Facultad de Periodismo y Comunicación Social, se presentó el proyecto "Mapas de aldeas: diagnóstico socio-comunicacional para la gestión de estrategias de comunicación/ desarrollo en el contexto de riesgo hídrico. Cartografías del territorio, construcción social de la salud y acceso a los derechos y políticas públicas". El mismo nuclea a seis facultades y varios centros de investigación y cuenta con cincuenta y dos investigadores. Este proyecto fue aprobado para su ejecución en marzo de 2014 y está en curso. Aquí sus primeros avances.

\section{FRAGMENTOS DE UN RELATO MODERNO}

En 1880 el Estado-Nación argentino aparecía apenas consolidado y frágil, emergente de una lucha constante entre Buenos Aires Puerto y el interior de las diferentes regiones del vasto Territorio por el control de la toma de decisiones. Había pujas y tensión por un proyecto de país que aún no se decidía si era Centralista o Federal, lo que se reflejaba en el control de la ciudad de Buenos Aires (entonces capital del Estado Nacional y del Estado Provincial que lleva su nombre al mismo tiempo). 
El fracaso del alzamiento porteño de 1880 concluyó entonces con la federalización de la ciudad de Buenos Aires como capital de la Nación, y Dardo Rocha, nombrado Gobernador de la Provincia de Buenos Aires tras la revuelta, se vio en la necesidad de instalar su gobierno y administración en otra ciudad. Una comisión compuesta por varios notables (por poder económico y por poder de conocimiento) se encargó junto a Dardo Rocha de elegir entre diversas localidades la instalación de la nueva capital. Los parámetros de selección eran la conveniencia para la administración de la Provincia de Buenos Aires y la calidad de los terrenos para la edificación, y de los circunvecinos para la agricultura. El propósito era construir obras indispensables para la higiene y comodidad de un gran centro poblacional, contemplándose para éste objetivo el acceso a suficientes fuentes de agua potable para sustentarlo. aparición en la segunda mitad del siglo XIX, cuando la psiquiatría pasó de contemplar la noción de delirio como observación de la locura a la nueva noción de contemplar los instintos. Foucault (2000) señala que:

en el fondo, esta transformación permitió un inmenso proceso que en nuestros días aún no ha concluido, el proceso que hace que un poder psiquiátrico intra-asiliario (noción de encerrar) centrado en la enfermedad, haya podido convertirse en jurisdicción intra y extra asiliaria no de la locura sino de lo anormal y de cualquier conducta considerada anormal.

Encerrar el discurso del loco o considerar que lo diferente a lo permitido es anómalo e inferior, es un claro ejemplo de la práctica cotidiana ejercida por la potestad del discurso dominante frente a cualquier otro discurso diferente que lo contradiga.

\section{Uno de los desafíos más difíciles será el de transformar nuestro pensamiento hacia un conocimiento y reconocimiento de la vida humana en toda su complejidad.}

A mediados del siglo $\mathrm{XX}$, con el final de la Segunda Guerra Mundial, un nuevo escenario se comenzó a consolidar a nivel global, dándose una nueva división del mundo en la crea-
La modernidad, comprendida como el momento histórico cuyo vector característico es una sociedad de producción basada en la acumulación y con un anhelo de felicidad que encuentra satisfacción en el progreso continuo. Este macro-relato entró en tensión durante todo el siglo XX y cayó por la pendiente del ego y la ambición desmesurada después de la guerra del petróleo en los años 70, con la consiguiente revolución científico-tecnológica hasta el presente, en que el relato principal es el proyecto de globalización.

Este proceso de injusta distribución de la riqueza (riqueza cuyo respaldo está dado por los recursos naturales de la Tierra más la inteligencia arrogante y racional que piensa que la domina) excluye a inmensas mayorías de diferentes culturas de la tan anhelada felicidad moderna y globalizada. Touraine (2006) señala que:

a partir de ahora, la modernidad definida por la eficacia de la racionalidad instrumental, por la dominación del mundo que la ciencia y la técnica hacían posible, no da una idea completa de la modernidad e incluso oculta su otra mitad: el surgimiento del sujeto humano como libertad y como creación.

Es difícil hoy en día asociar a la modernidad con los principios de Igualdad, Libertad y Fraternidad cuando ésta es excluyente por definición. Todo lo que queda afuera, como la inmensa mayoría de la América profunda, es considerado inferior, disfuncional o anormal. Este concepto de anormalidad es revisado por Foucault, que ubica su ción de un mapa político bipolar. Por un lado, se encontraba Estados Unidos como principal representante del sistema capitalista y, por el otro, la Unión Soviética, que se erigía en contraposición a esas ideas, ofreciendo un orden económico y social alternativo al anterior.

En este escenario, Latinoamérica quedó signada bajo las políticas imperialistas del Estado del norte, y atrapada en la disputa por la hegemonía mundial dentro de un paradigma funcional a los intereses estadounidenses. En palabras de Melano (2000):

la política de Estados Unidos hacia los países latinoamericanos $[. .$.$] se había centrado en tres ejes [...] expandir y$ hegemonizar el capitalismo a nivel mundial, abaratar costos de materias primas y mano de obra para dar respuestas a su expansión y evitar el 'peligro' comunista en la región, móvil utilizado para enmascarar el expansionismo económico.

Desde 1958, evaluadores externos, libros traducidos, programas, planes y proyectos comenzaron a arribar a Argentina, con las 'recetas' para dejar de ser un país 'subdesarrollado'. Asimismo, se comenzaron a establecer alianzas entre la burguesía local y los representantes del capitalismo extranjero. Esto trajo aparejado la modernización de la organización empresarial, la reestructuración económica a través de la consolidación de oligopolios y la mayor tecnificación de la mano de obra para los puestos de trabajo, además de consolidar el crecimiento de capitales extranjeros en detrimento de la industria nacional y los pequeños y medianos productores, entre otras consecuencias. 


\section{CRÍTICA A LOS RELATOS}

\section{MODERNIZADORES Y EMERGENCIA DE UN NUEVO PARADIGMA}

Los seres humanos como parte de un cosmos (el universo concebido como un todo ordenado por oposición al caos) deberíamos repensar nuestros valores, relaciones y prácticas. La pedagogía de este tiempo debería desbordar los límites de la educación tradicional centrada en lógicas de competencia, acumulación, consumo y producción, lógicas que no contemplan la relación con la naturaleza y con los otros seres vivos. Tendría que partir de la premisa de sentir y vivir el hecho de ser parte de la Tierra, para entonces crear nuevas relaciones e interacciones para proteger la vida en cualquiera de sus formas. Uno de los desafíos más difíciles será el de transformar nuestro pensamiento hacia un conocimiento y reconocimiento de la vida humana en toda su complejidad.

Gutierrez y Prado (2000) expresan que "los descubrimientos de un nuevo paradigma científico, han ocasionado un profundo cambio en la visión del mundo, determinando el paso de una concepción mecanicista cartesiana y newtoniana a una visión holística y ecológica". La manera como miramos y nos relacionamos con la vida, con nosotros mismos, con los otros y con la naturaleza constituye nuestro Paradigma. ${ }^{1}$ La concepción lineal del mundo derivada de la ciencia mecánica nos dio una manera de mirar y actuar que fue aplastando y escondiendo otras formas de ver, de ser, hacer y estar en el mundo.

Hay un cauce ${ }^{2}$ de la historia que circula por debajo por ejemplo, la concepción de habitar el mundo de los pueblos originarios y sus culturas- $y$ otro cauce que va por encima, que se impone al de abajo: el saber dominante, hegemónico, la voluntad de verdad de una época ${ }^{3}$. Este modelo dominante, antropocéntrico, moderno y occidental se caracteriza por separar, fragmentar; poner énfasis

1 Un paradigma es un marco de pensamiento, un esquema de referencias para entender y explicar ciertos aspectos de la realidad. Proviene del griego; su significado es 'patrón'.

2 Le llamo cauce a un espacio por donde circula la producción de sentidos como hecho cultural.

3 "Pues esta voluntad de verdad, como los otros sistemas de exclusión, se apoya en un soporte institucional: está a la vez reforzada y acompañada por una densa serie de prácticas como la pedagogía, como el sistema de libros, la edición, las bibliotecas, las sociedades de sabios de antaño, los laboratorios actuales. Pero es acompañada también, más profundamente sin duda, por la forma que tiene el saber de ponerse en práctica en una sociedad, en la que es valorizado, distribuido, repartido y en cierta forma atribuido" (Foucault, 1992: 10). en 'tener', generar dependencia y exclusión; ser patriarcal, utilitarista y reduccionista; mecanicista y lineal, tóxico y contaminante y se propone a sí mismo como pensamiento único y verdadero. Desde el paradigma moderno el hombre se cree dueño de todo, de la tierra, del agua, de los otros, del conocimiento, del tiempo.

La ciencia occidental no es ajena a estos cambios y por esto sufre rupturas y revoluciones. Los descubrimientos de la física cuántica ${ }^{4}$ los nuevos planteamientos de la biología y las matemáticas, algunos estudios de la teoría de sistemas han dejado sin piso al mecanicismo positivista que ha sido, hasta hoy, la manera políticamente correcta y hegemónica de entender la realidad.

Muchas concepciones nos van a dar las respuestas, una de ellos -tal vez la más clara- es la de la Tierra como organismo vivo. Las sabidurías ancestrales de los pueblos originarios nos recuerdan que hay otras maneras de sentir y ver que todo está relacionado, que nada se mueve sin la complicidad del todo. Rescatamos de ellas la relación del ser humano con la Tierra como organismo vivo (criticada por el pensamiento racional como pensamiento mágico que anima... ¿lo quieto?, ¿o lo inexistente porque no piensa?, ¿ం lo 'cosa' porque no habla?). Respuestas como el cambio climático, que hoy parece ser el único motivo de inundación de la Ciudad de La Plata, nos invita a dejar atrás esta idea moderna del uso y la explotación de la Tierra a cualquier precio, la idea del progreso continuo, de la dominación de la naturaleza, de la dominación del hombre por el hombre para cualquier fin.

La modernidad está en crisis: hay crisis de representatividad, crisis de partidos políticos, crisis de la democracia como sistema, crisis en la educación, en los valores, hay crisis de contaminación. ¿Cuáles son las respuestas que la ciencia moderna tiene para estos problemas? ¿Por qué las ciencias económicas subordinan los saberes aprehendidos

4 La física cuántica es una de las ramas principales de la física que explica el comportamiento de la materia. Comienza al principio del siglo XX. Su campo de actuación es el de las partículas elementales, entendiendo como tales las que componen la estructura más elemental de la materia. El estudio de estos componentes básicos ha descubierto que el mundo subatómico se desenvuelve de manera misteriosa para la percepción ordinaria y que las leyes de los objetos físicos no pueden aplicarse en el ámbito de las partículas elementales. La gran constatación es que las ondas y partículas que componen el universo cuántico intercambian su naturaleza constantemente siendo ondas por la mañana y partículas por la tarde o viceversa. Además, se comunican entre sí a pesar de las enormes distancias que las separan y recorren el tiempo en dos direcciones: hacia el pasado y hacia el futuro (Consultado en : http:// www.webzinemaker.com/admi/m6/page.php3?num_ web=1604\&rubr=4\&id=5581). 
y manifestados por las ciencias políticas, las otras ciencias sociales, las ciencias naturales y las ciencias exactas, actuando como si éstas no existieran?

En este momento de transición entre un modelo implotado' y la creación de otro modo de estar en el mundo, la comunicación tiene un rol protagónico que va mas allá de la información: es la capacidad de poner cauces para producir nuevos sentidos y para disparar procesos de reflexión y multiplicación de otros discursos que pongan en tensión los discursos hegemónicos.

Desde fines del siglo XX, una de las disputas más significativas en la Argentina - como en toda América Latinasurge por los bienes naturales. Según Giarraca (2006):

esto sucede desde que el capital, en sus formas más avanzadas y transnacionalizadas, tomó como centro importante de su valorización a los recursos naturales. En efecto, en los últimos veinte años vimos aparecer procesos de apropiación de la naturaleza dentro de nuevos campos de valorización del capital. La idea de desarrollo de estos nuevos tiempos implica la dominación de los recursos, sobre todo el agua, la energía y la diversidad biológica.

\section{EL PARADIGMA EMERGENTE: RELACIONAL Y AUTORGANIZACIONAL}

Con sencillez y sentido común, desarrollo a través de toda esta reflexión epistemológica, política y compleja, la idea de que el ser humano tiene que dar un salto cualitativo en su forma de vivir y eso debe llegar rápido a las organizaciones sociales y calar hondo en la cultura. Este cambio debería ser evidente y promovido desde muchos espacios y dimensiones, desde los procesos educativos, desde la universidad, desde la planificación y gestión de las políticas públicas, desde los medios de comunicación o desde las acciones en nuestras vidas cotidianas: un orden del pensamiento humano donde las personas buscan y anhelan sentirse en comunión -común-unióncon los otros y con la naturaleza, viven la vida como un proceso, buscan otras explicaciones por encima de todo dogmatismo, se hacen preguntas, se ven a sí mismos como parte de un todo, no desdeñan la espiritualidad o el humanismo y conciben al universo como una red de relaciones dinámicas.

"Comunicar es poner en común, desatar procesos de encuentro con otras personas con las que podemos intercambiar miradas, palabras, gestos, sentimientos, ideas, recursos, pasiones" (Ceraso et al., 2011). La comunicación, muchas veces aún, es enseñada como un proceso de transmisión de mensajes de un emisor a un receptor utilizando un canal. Esta mirada puede ser explicada desde el modelo matemático originado en la década de 1940 en Estados Unidos por Shannon y Weber, en el que la eficacia de la comunicación se mide a través de la fidelidad de la recepción, es decir, cuando el destinatario recibe exactamente lo que la fuente ha originado como mensaje a transmitir. Para que la transmisión de la información de un punto a otro sea exitosa, es necesario que no exista 'ruido' que afecte la circulación del mensaje.

Es importante entender que Shannon y Weber eran ingenieros, estaban sistematizando un modelo de comunicación telefónica y su objetivo era optimizar la comunicación desde una perspectiva tecnológica. Desde este modelo informacional inicial hasta hoy se dieron conceptualizaciones, aportes y reformulaciones en diferentes momentos del proceso y desde diferentes disciplinas. Desde el terreno de la lingüística estructural, Román Jacobson aportó otra dimensión de análisis al modelo matemático cuando incorporó el concepto de 'contexto' en el momento en que se produce la transmisión de los mensajes, así como las diferentes funciones que puede cumplir el lenguaje.

Los estudios de la escuela funcionalista ${ }^{5}$ producirán avances sobre ese modelo al considerar la influencia de los medios de comunicación en la sociedad, el rol de los grupos de pertenencia, los efectos en las audiencias, todo desde la teoría del emisor. La teoría crítica, por su parte, aportará su perspectiva desde una conceptualización del poder y la sociedad de masas, donde los medios de comunicación se integran a las fuentes de poder y a las autoridades para construir y ejercer hegemonía. Desde esta línea teórica se ponen de manifiesto la ideología y la manipulación en los procesos de comunicación.

En un momento el papel del receptor, como subsidiario del esquema de comunicación (que solo parece modificarse cuando ocupa el lugar del emisor), lleva a éste proceso de conocimiento a realizar nuevas proposiciones con las perspectivas de diferentes disciplinas como la semiótica, la teoría literaria y algunas miradas sociológicas como las representadas por los estudios culturales ingleses, que permiten la superación de esta mirada pasiva acerca del receptor y lineal sobre la comunicación. Se considera entonces a las prácticas comunicativas como espacios de interacción entre sujetos (activos protagonistas del acto comunicativo) en los que se observan procesos de producción de sentido.

5 El nombre de esta escuela se deriva del hecho de que las culturas se presentan como todos integrados, funcionales y coherentes. Por lo tanto, cada elemento aislado de la cultura sólo puede analizarse considerando los demás. 
Para Cristina Mata (1990):

los emisores ya no transmiten unos mensajes significados elaborados en virtud de un instrumento neutro. Tanto en la esfera de la emisión como en la de la recepción existe producción de sentido y no mera transferencia de los primeros a los segundos, aún cuando ella sea desigual, no simétrica... De aquí que podamos recuperar para la comunicación la idea de contrato o negociación, donde ambas partes -emisores y receptores- son activas, permaneciendo diferenciados en sus roles y su capacidad de operar. Es aquí que, reconociendo el indiscutible poder del emisor debemos advertir en su discurso la presencia activa de los receptores porque ellos están presentes como término de su producción como el otro que habla en lo que yo digo.

Las perspectivas que vamos encontrando en el proceso histórico de la comunicación, como dominio de saber, llevan implícita una forma de ver el mundo y se corresponden con un modo conceptual o teórico de ver a la sociedad y sus relaciones. Estas miradas guardan relación profunda con el contexto político en que surgieron y con las características de los procesos de comunicación que describen.

\section{SABER, PODER Y COMUNICACIÓN}

Considero de vital importancia traer a Antonio Pascuali y Paulo Freire al marco teórico de esta investigación, primero porque los considero punto de partida a la hora de pensar los estudios sobre comunicación en América Latina, y también porque estos autores, en la misma época, por los años sesenta, pensaron las relaciones entre saber, poder y comunicación desde un contexto latinoamericano. Dice Pascuali (1963):

La filosofía ha rechazado siempre un saber incomunicable, o ha determinado desde su comienzo que lo incomunicable es lo incognoscible, y lo incognoscible no es, pues supone que lo inexpresable es alógico y lo alógico una 'agnóia' o no saber. Por lo tanto, el grado y modo de su comunicabilidad define pues, a un saber como éste define a su plexo social; de lo cual puede inferirse directamente en perspectiva sociológica, una mutua inherencia dialéctica entre los medios de comunicación del saber y su correspondiente grupo social. Sólo hay sociedad o estar-uno-con-otro donde hay un con-saber y sólo hay con-saber donde existen formas de comunicación.

Desde este punto de vista es necesario agregar a lo dicho por Pascuali una mirada no centrada únicamente

en los medios sino que incluya también las mediaciones, cuestión tratada más tarde por Jesús Martín Barbero. Sería imposible que exista un con-saber si no hay comunicación. La sociedad que habita el territorio donde está inserta nuestra universidad pública tiene derecho a conocer, a través de una estrategia coherente de comunicación -y cuando digo comunicación no estoy hablando solo de información- el conocimiento que ésta universidad tiene acerca del riesgo hídrico.

En este sentido la universidad, al pensar a sus receptores, debe considerarlos sujetos de conocimiento, pues los necesita a la hora de saber cómo suceden los acontecimientos en el seno mismo de las prácticas sociales. Y los espacios de comunicación y reflexión donde éstos diálogos de saberes ocurran, darán los argumentos necesarios que serán insumo para la toma de decisiones. Retomando a Pascuali (1963): "comunicación entendida así es pues un término privativo de las relaciones dialógicas interhumanas". Encontramos en éste maestro el concepto de con-saber, que aún sin salirse de la relación lineal entre emisor-mensaje-receptor, pretende una revalorización del receptor como sujeto de conocimiento y no como sujeto pasivo. Cada individuo conlleva un saber que le permite relacionarse en sociedad. El saber parte de la experiencia concreta. De la trama de relaciones dentro de la cual los seres humanos nos movemos. Por esto, todo saber es social.

\section{En este momento de transición entre un modelo 'implotado' y la creación de otro modo de estar en el mundo, la comunicación tiene un rol protagónico que va mas allá de la información.}

\begin{abstract}
Sólo es pues, auténtica comunicación la que se asienta en un esquema de relaciones simétricas, en una paridad de condiciones entre transmisor y receptor y en la posibilidad de oír uno a otro o prestarse oídos (Heiddeger), como mutua voluntad de entenderse (Pascuali, 1963).
\end{abstract}

Nos proponemos, en la presente investigación, generar diálogos de saberes entre universidad y sociedad, diálogos donde se encuentra la problematización del propio conocimiento. Este conocimiento no puede ni debe estar fuera del marco de la realidad, para poder comprenderla, explicarla y transformarla.

Por su lado Freire, atravesado por el mismo momento histórico, inserto en las prácticas sociales y pensando desde el dominio de saber de la educación, pensó la diferenciación entre extender tecnología (en el marco del desarrollismo y la Alianza para el Progreso) y comunicar acerca 
de ella buscando el camino del conocimiento. También Freire (2004) analiza la relación emisor-mensaje-receptor sin salirse de la linealidad, pero sacando al receptor de esa imagen de subsidiariedad que lo presenta como un sujeto pasivo, lo cosifica, lo pone en el lugar del ignorante frente al poder inconmensurable del emisor. Paulo Freire asigna a la educación la función de ser la práctica social de humanizar al hombre en la acción consciente que éste debe hacer para transformar el mundo. Dice (Freire, 2004):

Conocer no es el acto a través del cual un sujeto transformado en objeto, recibe, dócil y pasivamente, los contenidos que otro le da o le impone... En el proceso de aprendizaje, sólo aprende verdaderamente aquel que se apropia de lo aprendido, transformándolo en aprehendido, con lo que puede, por eso mismo, reinventarlo; aquel que es capaz de aplicar lo aprendido/aprehendido a las situaciones existenciales concretas. Por el contrario, aquel que es 'llenado' por otro de contenidos cuya inteligencia no percibe, de contenidos que contradicen su propia forma de estar en su mundo, sin que sea desafiado, no aprende. saber' hasta la 'sede de la ignorancia', para 'salvar', con este saber, a los que habitan en aquella. Por el contrario educar y educarse es tarea de aquellos que saben que poco saben - por esto saben que saben algo, y pueden así llegar a saber más-, en diálogo con aquellos que, casi siempre, piensan que nada saben para que éstos transformando su pensar puedan igualmente saber más (Freire, 2004).

La educación, dice Freire, es comunicación, es diálogo, en la medida en que no es la transferencia de saber, sino un encuentro de sujetos interlocutores que buscan significaciones. La comunicación implica una reciprocidad que no puede romperse. No es posible comprender el pensamiento fuera de su doble función: cognitiva y comunicativa. No hay pensamiento aislado así como no hay hombre aislado.

\section{LA COMUNICACIÓN EN AMÉRICA LATINA}

En América Latina los estudios sobre comunicación encuentran la influencia de diferentes formas de conceptualización ligadas a la situación política del momento y a las teorizaciones de otras regiones del mundo. En los sesenta y setenta, la influencia de Estados Unidos en pleno proyecto de la Alianza para el Progreso propone el uso que se hace de la comunicación desde una mirada difusionista. La

Es aquí donde se da la integración entre comunicadoreducador en la práctica social, donde se aprehende la realidad. Es aquí desde donde comienza un proceso de diálogo, desde donde nos reconocemos como sujetos capaces de transformar dicha realidad. Freire analiza como objeto el término extensión. Entiende por extensión el acto en el cual el sujeto activo (el que extiende) transmite un contenido. La extensión según esta concepción es una entrega (de algo que es llevado por un sujeto que se encuentra 'atrás del muro', a aquellos que se encuentran 'fuera del muro'). Es por eso que, entendida de este modo, la extensión supone un mesianismo por parte de quien extiende, al mismo tiempo que una superioridad basada en los contenidos de quien entrega y una inferioridad de los que reciben. En términos comunicacionales podría decirse que el énfasis y el poder están puestos en el emisor. Ve a esta extensión como mecanicista (en la acción de quien extiende) y como invasión cultural (a través del contenido llevado que refleja una visión del mundo diferente que se superpone a la visión del mundo de los que supuestamente en forma pasiva reciben estos contenidos):

Educar y educarse, no es extender algo desde la 'sede del comunicación se ve como insumo estratégico del cambio y tiene base en las teorías funcionalistas. La comunicación y los medios son utilizados como herramientas para la modernización, y se entiende a la comunicación como un medio para superar la brecha tecnológica entre América Latina y las naciones 'desarrolladas'.

Por otro lado, es importante la influencia de teóricos europeos. Si bien pensadores como Pasquali y Freire reciben la influencia de la Escuela de Frankfurt, el marxismo, el estructuralismo o la semiología, desde su propio marco comienzan a ver a la comunicación de masas no sólo como instrumento de dominación sino también como estrategia para la liberación. De alguna forma se diferencian de los teóricos europeos por cómo miraban la comunicación y la utilización que se podía hacer de ella. Como se ha dicho en páginas anteriores, Freire, en ¿Extensión o Comunicación? (2004) critica la noción de comunicación basada en la transferencia de un sujeto activo que tiene el poder a uno inferior que es manipulado, para pensarla como un proceso interactivo entre sujetos a fin de servir a la problematización de la realidad para su transformación. Si bien los funda- 
mentos teóricos en los que se basaban estos autores no eran latinoamericanos, sí lo eran las experiencias a las que eran aplicados y sobre las que luego se reflexionaba y se producían nuevos y propios saberes.

Otro punto de partida para mirar la teoría de la comunicación en América Latina es Jesús Martín Barbero y su obra De los medios a las mediaciones (1987), en donde se plantea que: "la cultura es la gran mediadora de todo proceso comunicativo", y propone el concepto de mediación, desde donde se otorga sentido al proceso. Barbero argumenta que mensajes, canales, emisor y receptor son parte de lo cultural, desaparecen como entidades separadas y deben estudiarse inmersos en las prácticas cotidianas. A partir de aquí se deja atrás el marco de análisis del mensaje para mirar el sentido construido desde los mensajes y en relación con los sujetos.

J. Díaz Bordenave (1987) expone que: "el individuo pasa a ser un elemento activo y no un simple objeto de la comunicación”. Se da como debate revelar el papel de los medios, las corporaciones y los ámbitos de poder como constructores de hegemonía. La comunicación y los medios son vistos como práctica cultural, y la industria cultural como nueva vía de expansión de la cultura popular, acentuada por las nuevas tecnologías de información y comunicación.

En este período el interés se centra en el hombre de todos los días, se pasa a mirar la recepción activa de los sujetos y cómo estos entran en contacto, se relacionan con la estructura dominante y el poder. Se focaliza en las prácticas de resistencia, negociación, apropiación y en los diferentes usos. Esta visión, que es realmente nueva y transformadora, reemplaza a aquella que veía a los sujetos, en el proceso comunicativo, como receptores pasivos y que predominaba en las reflexiones de antes de los años ochenta. A fines de esa década la dinámica del proceso comunicativo se mira en las prácticas, en los medios, la cultura, los públicos populares, sin abandonar los productos o mensajes. Se instala la concepción y la mirada de la recepción en los trabajos. Los interrogantes se focalizan hacia los usos, percepciones, apropiaciones y re-semantizaciones.

Se puede concluir entonces que la investigación en comunicación en América Latina parte de recuperar los valores, visiones y memoria del pueblo, para construir una mirada diferente a la de las teorías hegemónicas. La comunicación aparece, pues, como vehículo para la transformación social.

\section{UNA METÁFORA Y SU RETORCIDA HISTORIA}

Generalmente la idea de desarrollo está asociada con progreso, es una noción que se percibe linealmente en tiempo y espacio. Está atravesada por lo económico como dominante y lo antropocéntrico como sustentación. Es difícil, desde esta idea, incorporar otras nociones como desear, sembrar, intuir, anticipar. Todas éstas son causa y efecto al mismo tiempo: son verbos, procesos. Si no están visualizadas, no es posible ver la complejidad de los procesos, ni tampoco salir de la linealidad.

Para Gustavo Esteva (1996) el concepto desarrollo

no puede desligarse de las palabras con las cuales se formó -crecimiento, evolución, maduración. Del mismo modo, quienes la emplean actualmente no pueden liberarse de la red de sentidos que da una ceguera específica a su lenguaje, su pensamiento, su acción. No importa el contexto en que se emplee, o la connotación precisa que la persona que lo usa quiere darle, la palabra se encuentra calificada y coloreada por significados acaso indeseables. La palabra implica siempre un cambio favorable, un paso de lo simple a lo complejo, de lo inferior a lo superior, de lo peor a lo mejor. La palabra indica que uno lo está haciendo bien, porque avanza en el sentido de una ley necesaria, ineluctable y universal y hacia una meta deseable.

El concepto de desarrollo fue mutando a lo largo de la historia, hasta convertirse en un concepto centralmente económico, que encontró fundamento en las 'carencias' como excusa para impulsar el crecimiento de las naciones pobres. Esta mirada economicista tiñó de alguna manera las valoraciones sobre la vida en sociedad durante toda la modernidad. Dice Esteva (1996):

Hacia 1800, Entwichlung comenzó a aparecer como verbo reflexivo. El autodesarrollo se puso de moda. Dios, entonces, comenzó a desaparecer de la concepción popular del universo. Unas décadas más tarde, se abrieron todas las posibilidades al sujeto humano, autor de su propio desarrollo, emancipado del designio divino. El desarrollo se convirtió en la categoría central del trabajo de Marx: lo mostró como un proceso histórico que se desenvuelve con el mismo carácter necesario de las leyes naturales. Tanto el concepto hegeliano de la historia, como el concepto darwinista de la evolución se entrelazaron en el desarrollo, reforzados en el aura científica de Marx.

Desde esta valoración que asocia el desarrollo a un proceso natural, se lee al mundo en términos de desarrollo- subdesarrollo. La meta para los países pobres es llegar al estamento superior, unívoco: a ser desarrollados- civilizados. Sigue Esteva (1996):

En el lenguaje ordinario, el desarrollo describe un proceso a través del cual se liberan las potencialidades de un objeto u organismo, hasta que alcanza su forma natural, completa, hecha y derecha. De aquí se deriva el uso me- 
tafórico del término para explicar el crecimiento natural de plantas y animales. Por medio de esta metáfora, se hizo posible mostrar la meta del desarrollo y, mucho después, su programa.

Para dos terceras partes de la gente en el mundo, sin embargo, este significado positivo de la palabra "desarrollo" -profundamente enraizado tras dos siglos de construcción social- es un recordatorio de lo que no son. Les recuerda una condición indeseable e indigna. Para escapar de ella, necesitan hacerse esclavos de las experiencias y sueños de otros (Esteva, 1996).

\section{APUNTES SOBRE EL ESTADO DEL ARTE EN COMUNICACIÓN Y DESARROLLO}

Los estudios pioneros realizados por investigadores norteamericanos que mencionan a la comunicación al servicio de la modernización y el desarrollo, por otro lado, fueron los puntos de partida para que, en la década del 1970, los investigadores latinoamericanos como Pascuali, Beltran y Díaz Bordenave, entre otros, plantearan también sus propuestas sobre el desarrollo. Éstos llegaron a definir la comunicación como un proceso que es inseparable de los procesos sociales y políticos necesarios para el desarrollo nacional y la independencia.

Dichos postulados fueron críticos con respecto a algunas propuestas foráneas en relación al desarrollo, por considerarlas fuera de la realidad. Su más dura crítica apuntó hacia la creencia equívoca de que la comunicación por sí misma puede generar desarrollo, independientemente de las condiciones históricas, socioeconómicas y políticas. Dichos investigadores elaboraron un nuevo paradigma que sostenía la idea de que la comunicación es un derecho fundamental de los seres humanos y que como tal, debe ser horizontal y participativa.

En los ochenta, con el desarrollo de nuevas tecnologías y el retorno -y posterior crisis- del sistema democrático, el escenario político, económico y comunicacional latinoamericano cambió significativamente el paradigma. La preocupación por plantear las políticas de comunicación para el desarrollo desapareció de la agenda de la UNESCO. El movimiento de intelectuales e instituciones sociales -ONGs, sectores de la iglesia, gremios sindicales, movimientos vecinales, etc.- comprometidos con este ideal terminaron refugiándose en la denominada comunicación alternativa. Al cabo de unos años, muchas de las organizaciones que cité anteriormente fueron percibiendo las voluntades y las limitaciones de las propuestas que se sustentaban en la comunicación alternativa, y partiendo de las limitaciones empezaron a cuestionarse sobre su trabajo, planteando la necesidad de realizar un trabajo educativo pero en el espacio de lo masivo.

Éste es el momento en que muchas de estas organizaciones deciden participar en los medios masivos impulsando emisoras y programas de radio, video, revistas especializadas, etc. Hay que precisar, sin embargo, que la opción inicial de acceder al espacio de lo masivo muestra una experiencia en la que lo educativo aparece 'reñido' con el entretenimiento. La concepción educativa tenía una carga ideológica muy fuerte, pero además, tenía un carácter sesgado a lo instructivo, lo cual me lleva a decir que el entretenimiento era visto como lo banal y sin importancia política.

La comunicación muestra la misma tendencia de crecimiento en todos los países latinoamericanos durante esa década, pero además el fenómeno de la globalización de la economía, la cultura y las comunicaciones aparece cada día como la nueva realidad a tomar en cuenta al momento de pensar la relación entre comunicación y desarrollo.

\section{UNA MIRADA EDUCATIVA}

Respecto al aprendizaje como proceso dice el comunicador y educador Francisco Gutiérrez (2000):

La educación en el paradigma actual, se lleva a cabo sobre todo por la enseñanza. Las instituciones de educación, primaria, secundaria, universitaria, son en realidad instituciones de enseñanza. Así lo demuestran las currículas, los planes de estudio, horarios, exámenes. La enseñanza que está centrada en el enseñante en sí es vertical, lineal, fragmentada, descontextualizada, muchas veces trasnochada y rutinaria. Con esto no pretendemos que se suprima la enseñanza en el nuevo paradigma: no se suprimirá si la enseñanza promueve el aprendizaje...

En la actualidad se ha ampliado tanto el concepto de aprendizaje que ya no queda restringido a la oferta de la escuela; siempre se está aprendiendo, ya sea de las relaciones cotidianas, de algún relato, de la observación, de los medios (Prieto, 1995). Se ve aquí a la educación como un proceso permanente de acción - reflexión - acción en el cual los sujetos que participan pueden 'entre-aprenderse'.

Se puede caracterizar el proceso educativo mediante una frase de Paulo Freire (2004): "La educación es praxis, reflexión y acción del hombre en el mundo para transformarlo". De esta manera, la educación es un proceso permanente en el que el sujeto va descubriendo, elaborando, haciendo suyo el conocimiento; él hace desde su realidad, desde su experiencia, desde su práctica social junto a los demás. Los participantes son los que le dan sentido al proceso. 
De este proceso también es parte el 'educador', ya no como el que enseña y dirige, sino para acompañar al otro, para estimular ese proceso de análisis y reflexión, para facilitárselo; para aprender junto a él y de él; para construir juntos. Según Gutiérrez existen siete elementos constitutivos de un proceso educativo: los sujetos o actores del proceso, el problema o necesidad sentida, el lugar (comunidad, espacio) donde se lleva a cabo el proceso, el tiempo de desarrollo (ritmo y secuencia de actividades), las relaciones intersubjetivas y con el entorno, los recursos (endógenos y exógenos), los resultados o productos.

Todo proceso educativo tiene resultados previstos y muchos otros que no se prevén, que surgen de la interacción de estos elementos. Para Prado y Gutiérrez (1997) “el proceso es dinámico, imprevisible y sorprendente, como lo es la vida misma, nuestra actitud tiene que ser de búsqueda, de sorpresa, de chispazos intuitivos, en suma, de enfrentamientos creativos con la incertidumbre”.

Los procesos educativos son sinérgicos y holísticos. Esto quiere decir que las propiedades y energía del proceso no son iguales que la suma de las partes intervinientes, pues en el proceso emergen nuevas propiedades del todo. Un proceso vivencial debe hacerse desde adentro y desde el todo, no se puede hacer en sumatoria y de forma fragmentada, sin integrarse. Partimos pues de un modelo de educación que promueva la producción de nuevos sentidos, valores y prácticas. Siguiendo a Francisco Gutiérrez y Cruz Prado (1997), educamos desde y para la incertidumbre, lo que significa interrogar de forma permanente a la realidad, no transmitir respuestas o recetas: localizar, reconocer, procesary utilizar información. Tratar de resolver problemas. Reconocer y desmitificar las propuestas mágicas de certidumbre. Crear, recrear, utilizar y problematizar los recursos tecnológicos. Educamos para la vida, para la significación y para la toma de decisiones, para la expresión, la construcción de autonomía y la autopoiesis: para convivir. Y lo hacemos reconociendo, dialogando y respetando las diferencias, para hacer propia la historia, la memoria y la cultura.

Considerando que uno de los componentes esenciales en un camino de desarrollo endógeno, sea este subjetivo o colectivo, es la educación; y contemplando las falencias de los sistemas educativos de los Estados-nación en América Latina, entendemos que la comunicación educativa en espacios formales y no formales fortalece la forma de aprender y darse cuenta de los pueblos y abre un cauce que posibilita la construcción de sentidos de las transformaciones.
Se entiende a la mediación pedagógica como la posibilidad de mediar entre áreas del conocimiento y de la práctica humana, y quienes están en situación de aprender algo de ellas. En la mediación pedagógica se conjugan cuatro elementos básicos: (1) partir siempre del otro, (2) trabajar la información de manera pedagógica, (3) trabajar las propuestas de aprendizaje también de manera pedagógica, y (4) trabajar en el tratamiento de la forma, ya que ésta educa como parte del acto pedagógico y resulta fundamental para asegurar la mediación.

\section{EL ROL DE LA UNIVERSIDAD PÚBLICA EN SITUACIONES DE EMERGENCIA}

La Facultad de Periodismo y Comunicación Social (FPyCS) de la UNLP fue el lugar elegido por la Presidenta de la Nación, Cristina Fernández, nacida y criada en La

\section{Sólo aprende verdaderamente aquel que se apropia de lo aprendido, transformándolo en aprehendido, con lo que puede, por eso mismo, reinventarlo.}

Plata, como base de operaciones para acopiar y distribuir los recursos en una gigantesca acción llevada a cabo por jóvenes de diferentes organizaciones políticas, sociales y religiosas a los y las habitantes afectados por la emergencia hídrica del 2 de abril de 2013.

Esta emergencia puso en evidencia la compleja relación existente entre el Estado, las políticas públicas, el acceso a los derechos fundamentales y las organizaciones territoriales. Desde lo acontecido, las organizaciones tuvieron que reacomodar sus objetivos y finalidades en pro de acompañar a los damnificados en el proceso de reconstrucción del territorio y acceso a los derechos. La FPyCS, al mismo tiempo, tuvo una importante participación en ese proceso, poniéndose al servicio de la comunidad y trabajando en el operativo de distribución de los recursos que el Estado y la ciudadanía puso en común para mitigar la crisis.

En este proceso de interacción comunicativa encontramos modos de gestión, estrategias de comunicación, nuevas formas de relación y una dificultad de comunicación en la llegada de las políticas públicas a todas las familias y ciudadanos afectados por la emergencia hídrica. Entendimos que un mapa comunicacional del territorio, realizado desde las diferentes miradas de distintas disciplinas visualizaría y facilitaría la optimización de estas relaciones, poniendo como eje central el rol de las organizaciones como articuladoras de la demanda social y la capacidad programática y 
estratégica de cambio y las posibilidades de prevención que el Estado promueve. La FPyCS puede generar, desde los mapas como herramienta concreta de gestión de la comunicación, canales, mensajes y estrategias para mejorar y potenciar las relaciones de comunicación entre las políticas públicas y la comunidad afectada.

\section{La relación entre universidad pública y territorio}

La comunicación y el desarrollo surgen como campos disciplinares diferentes, pero en América Latina se asocian en prácticas y experiencias concretas de transformación de la realidad, que llevan adelante gran cantidad de actores políticos y sociales en territorios concretos. Desde la Secretaría de Integración con las Organizaciones de la Comunidad de la FPyCS de la UNLP y la Unidad de Prácticas y Producción de conocimientos (UDEP), se vienen realizando actividades de extensión desde esta perspectiva. Estas prácticas han producido saberes específicos, que permiten reconocer una serie de aportes (nociones, planes y proyectos, herramientas, estrategias, sentidos) que se dan en territorios concretos de transformación y cambio social. Pensar estos dos campos de manera asociada es el resultado de la puesta en juego de concepciones específicas sobre la comunicación y sobre el desarrollo, que desde la FPyCS se vienen articulando desde prácticas concretas de gestión del desarrollo endógeno.
Por lo tanto, el proceso de la investigación fortalecerá los encuentros comunicacionales y las redes de comunicación que se establecieron en la emergencia hídrica entre las distintas organizaciones de los barrios Villa Elvira, San Lorenzo, Los Hornos, Gambier, Melchor Romero, Tolosa, San Carlos, Villa Elisa y algunos puntos del cinturón frutihortícola del Partido de La Plata, para promover los modos de gestión que incidan en el fortalecimiento de redes territoriales existentes $\mathrm{y}$ emergentes. El proyecto apunta a generar mapas de redes territoriales en yuxtaposición con mapas de redes comunicacionales y su atravesamiento con las relaciones y prácticas entre comunidad, organizaciones, políticas públicas y acceso a los derechos.

También emprenderá un camino inédito e incierto, en el que diferentes disciplinas mirando desde sus distintas perspectivas buscarán un objetivo común sin anular las diferencias. Un camino que busca una racionalidad emancipadora en contraposición a la racionalidad dominadora, un conocimiento que tenga en cuenta otros conocimientos por más de que estén afuera del sistema moderno. Democratizar los diálogos para la producción de conocimientos es acortar esa brecha insostenible entre teoría y práctica, que convierte a la práctica en subalterna y la ubica en un lugar marginal, y a la teoría en reinante, repetitiva y quieta. A este modo de racionalidad, que nos retrasa y encierra coartando nuestra propia iniciativa, Boaventura (2005) la denomina la razón indolente.

Hoy vivimos un problema complicado, una discrepancia entre Teoría y Práctica social que es dañina para la Teoría y también para la Práctica. Para una Teoría ciega, la Práctica social es invisible; para una Práctica ciega, la teoría social es irrelevante.

La razón indolente se manifiesta de diferentes formas. Dos me parecen particularmente importantes: la razón meto-

Desde esta mirada, el desarrollo es endógeno y desde el lugar y requiere, para su surgimiento, de una condición que es medio y fin en sí misma: la búsqueda de los sentidos propios de la transformación, sentidos propios en los actores y los territorios que protagonizan los procesos de transformación de su realidad. Ahora bien, si entendemos a la comunicación como procesos de significación y producción de sentidos que nos permiten comprender el mundo, es condición necesaria para que una transformación sea posible. En este sentido, el campo de la comunicación y desarrollo surge en la asociación de dos campos disciplinares diferentes, que se unen en la búsqueda de conocimiento y en la producción de prácticas concretas, tendientes a fortalecer la producción de sentidos en procesos de transformación de la realidad de las comunidades. nímica y la razón proléptica.

La razón metonímica (...) esta es una racionalidad que fácilmente toma la parte por el todo, porque tiene un concepto de totalidad hecha de partes homogéneas, y nada interesa de lo que queda por fuera de esa totalidad. Entonces, tiene un concepto restringido de totalidad... Este modo de la razón indolente, que llamo razón metonímica, hace algo que, a mi juicio, es uno de los dos aspectos del desperdicio de la experiencia: contrae, disminuye, sustrae el presente.

La razón proléptica es la segunda forma. Prolepsis es una figura literaria, muy vista en las novelas, donde el narrador sugiere claramente la idea de que conoce bien el fin de la novela pero no va a decirlo. Es conocer en el presente la historia futura. Nuestra razón occidental es 
muy proléptica en el sentido de que ya sabemos cuál es el futuro: el progreso, el desarrollo de lo que tenemos. Es más crecimiento económico, es un tiempo lineal que de alguna manera permite una cosa espantosa: el futuro es infinito. A mi juicio, expande demasiado el futuro.

Este proyecto de investigación, orientado a prevenir y transformar algo tan concreto como el riesgo hídrico en el marco del cambio climático, apunta a democratizar el diálogo de saberes y propone poner cauces para emancipar la palabra con el objetivo de producir nuevos sentidos. Entre otros numerosos objetivos de conocimiento llevados a cabo por varios centros de investigación, realizará talleres de producción de mensajes propios con miembros de las organizaciones y la comunidad en los lenguajes radial, gráfico, audiovisual y artístico para poner en circulación en el territorio saberes y sentidos producidos durante y después de la emergencia hídrica en los espacios públicos. El carácter transdisciplinar de este proyecto nos permite también como universidad realizar otro diálogo de saberes que, integrando diferentes perspectivas, potenciará las acciones estratégicamente para lograr un abordaje integral del territorio.

Desde un principio la convocatoria a estos Proyectos de Investigación de Desarrollo Tecnológico y Social, realizada conjuntamente por la UNLP y el Conicet, fue concebida con la condición de que varias unidades académicas unieran sus recursos y saberes con un objetivo general que los encontrara en un propósito común, y con objetivos y resultados esperados específicos de conocimiento. Estos resultados de conocimiento pretenden hacer aportes concretos a la toma de decisiones con respecto a la emergencia hídrica, en relación con las políticas públicas, con los planes de contingencia y prevención y con el protagonismo de los ciudadanos y sus organizaciones para defenderse durante el desastre

\section{PERSPECTIVA METODOLÓGICA}

Nuestra perspectiva metodológica se basa en la construcción de conocimientos, desde la complejidad de procesos de gestión y planificación de la comunicación, en proyectos de cambio social y transformación integral de los territorios. Desde este enfoque, la realidad es dinámica y está en constante cambio. Es posible conocer para intervenir en la realidad, a fin de generar procesos de transformación en el sentido que nos proponemos. Esta mirada supone un enfoque transdisciplinar y participativo para construir el mapa comunicacional de una comunidad.
Para construir mapas desde procesos participativos, es necesario hacer recortes que nos permitan delimitar, en un adentro y afuera, lo que queremos conocer en profundidad. Estos límites, creados por nosotros, no son cerrados, sino que permiten un diálogo entre las condiciones internas y las condiciones externas. Cuando pensamos en la construcción de un mapa comunicacional, lo hacemos desde una mirada del desarrollo endógeno de las comunidades. Por lo tanto, no se construye mirando solamente la realidad actual, sino que lo pensamos en relación con el futuro deseado por los actores mismos de esas comunidades y con la historia que los y nos precede. Por lo tanto, desde una mirada del desarrollo endógeno, la construcción de mapas implica poner en relación la situación inicial con la situación deseada, no solo por nosotros, sino por la mirada participativa de los protagonistas de la comunidad.

La metodología de creación de mapas comunicacionales es una construcción que surge del mismo proceso de investigación. Por lo tanto, afirmamos que un mapa comunicacional se construye estratégicamente para acercarnos y enredarnos con las comunidades y luego hacer más comunicables los resultados de este proceso de participación. Ningún mapa de comunicación está definido con anticipación al proceso de investigación. Las definiciones surgen en cada fase de ésta investigación cartográfica. Ésta no es una afirmación que se fundamente en lo metodológico, sino en lo epistemológico. El conocimiento es un sistema conveniente que nos permite relacionar experiencias entre sí.

En el empirismo hay observables que constituyen el punto de partida de todo conocimiento. Son neutros (los mismos para todas las personas y disciplinas) y se dan en la percepción. Sin embargo, nosotros pensamos que para crear una cartografía que genere procesos de participación en las comunidades, hay que pensar al territorio desde la complejidad. Esto significa construir desde procesos participativos un 'trozo de la realidad' que incluye aspectos físicos, biológicos, sociales, económicos y políticos. El punto de partida es la pregunta guía o conjunto coherente de preguntas que hacen más especifica la orientación general de la investigación: ¿para qué nos sirve el mapa comunicacional?

Una cartografía tiene los siguientes componentes:

- Los elementos que aparecen como relevantes en el mapa.

- Los límites complejos del mapa.

- Sus interrelaciones, tanto internas como externas. 
Los mapas que representan la realidad empírica carecen de límites precisos en su extensión física y en sus problemáticas. De esto se desprende que es inevitable que impongamos límites en el mapa que pretendemos construir participativamente en diálogo con las comunidades. Esto implica dos problemas: (1) la definición de los límites del mapa de manera tal que reduzca la arbitrariedad en la partición que se adopte, y (2) las formas de tomar en cuenta las interacciones que se dan en el mapa, así definido, con el 'medio externo'. Dicho de otra manera, la influencia de lo que queda afuera sobre lo que queda adentro del mapa y, recíprocamente, las condiciones del entorno. Los elementos son los componentes de un sistema. No son independientes porque se determinan recíprocamente. Por esto, la elección de los límites debe hacerse de forma tal que los elementos presenten cierta forma de organización o de estructura. La estructura del sistema está dada por las relaciones entre los elementos. Por lo tanto deben ser incluidas las relaciones más significativas entre éstos; dejando relaciones con elementos que quedan afuera del mapa. Por ello las relaciones entre elementos conforman los límites del mapa y determinan sus condiciones de contorno.

nes de donde surgen. El instrumento-mapa debe ser construido en tres dimensiones: intraobjetual, interobjetual y transobjetual. Cada campo de relaciones es mirado desde dichos niveles de proceso.

Al reconocer estos cruces de campos (educación, salud, medio ambiente, medios de comunicación, etc.) y niveles de proceso (intra, inter y trans), surgen espacios de interacción de diferentes elementos de un mismo sistema, que configuran subsistemas de relaciones que nos disparan diferentes técnicas de investigación cuali-cuantitativas. La estructuración del sistema toma la forma de un mapa de relaciones que tiene varias posibilidades de entradas y combinaciones. Esta estructura es desestructurada, porque nos permite realizar varios recorridos por el campo material, disparando diferentes procesos de investigación/participación/acción, que pueden convivir y articularse en la misma estructura. Todo depende de dónde pongan el acento la comunidad y el grupo de investigación que participa en la construcción del mapa, con qué pregunta se enfoque el problema, qué subsistemas se configuren, con qué elementos se trabaje o con qué recursos materiales, humanos e institucionales cuente el grupo investigador.

Por otro lado la estructura también abre canales de circulación y diálogo entre diferentes componentes del sistema. Es decir que los distintos conceptos, descripciones, valores, situaciones, etc., que surgen desde

\section{Sobre la metodología: una estrategia}

A la hora de pensar metodológicamente nuestro proceso de creación del mapa hay que afrontar la definición de límites, su ecología; qué es lo que queda afuera y lo que ya está incorporado. Entonces podemos reconocer (desde una perspectiva amplia y compleja de la comunicación), diferentes campos en un mapa, que surgen de los temas que son significativos y relevantes para las comunidades que se apropiaran del mapa. Por ejemplo, algunos campos que se pueden cruzar en el mapa son: políticas públicas, universidad, jóvenes, salud, educación, comunicación, participación, medios de comunicación, mediadores, medio ambiente, trabajo, producción o género. Estos campos son ideas fuerza que, en el proceso de participación, constituyen relaciones posibles, donde vamos a encontrar qué es lo que vamos a construir específicamente.

\section{¿Qué vamos a observar específicamente?}

Los observables y los hechos se construyen intentando no perder la fuerza de la complejidad de la trama de relacio- los campos de relaciones, se combinan armónicamente al cruzarse en el proceso de investigación participativa. Recorremos el campo material de distintas formas, combinando preguntas y elementos, enfocando con diferentes instrumentos para construir la cartografía. Así, el nivel de proceso intraobjetual arroja los datos cuantitativos; el nivel de proceso interobjetual hace visible las relaciones; y el nivel de proceso transobjetual posibilita la transformación.

\section{La ecología del sistema}

Definimos los límites del mapa no como fronteras territoriales. Partimos de reconocer que no podemos mirar toda la realidad y que tenemos que ordenar el relato de una manera donde la separación entre el adentro y el afuera tenga condiciones en los límites, que faciliten el movimiento y el flujo. Es decir, establecer una convivencia entre los elementos que produzcan transformaciones, cambios imprevistos en la estructura del mapa y nuevas posibilidades de perspectivas. El mapa es el instrumento que estructura la investigación. 
Tabla: Estado actual del proyecto: dimensión política de construcción de conocimientos en la realidad territorial

\begin{tabular}{|c|c|c|c|}
\hline Nivel de Procesos & Modos de Conocimiento & Técnicas & $\begin{array}{l}\text { Dimensiones de la } \\
\text { realidad }\end{array}$ \\
\hline Intraobjetual & $\begin{array}{l}\text { Fenomenológico } \\
\text { Descripción de elementos en } \\
\text { detalle. }\end{array}$ & Distributivas Encuesta & Material y Objetiva \\
\hline Interobjetual & $\begin{array}{l}\text { Objetivizante Sistemas de } \\
\text { relaciones entre elementos. } \\
\text { Organización: tipo de } \\
\text { relaciones que garantizan la } \\
\text { identidad del objeto. }\end{array}$ & $\begin{array}{l}\text { Estructurales Reflexivas } \\
\text { Grupos de discusión. Historia de vida } \\
\text { Trayectoria } \\
\text { Cartografía cultural }\end{array}$ & $\begin{array}{l}\text { Valores subjetivos de la } \\
\text { gente }\end{array}$ \\
\hline Transobjetual & $\begin{array}{l}\text { Praxeológico Capacidad de } \\
\text { transformar. }\end{array}$ & $\begin{array}{l}\text { Intervención Investigación acción. } \\
\text { Diálogos de saberes. } \\
\text { Redes de relaciones- } \\
\text { 'Entreaprendizajes' de la } \\
\text { transformación Social. } \\
\text { Trabajo heurístico. }\end{array}$ & Potencial de desarrollo \\
\hline
\end{tabular}

Las experiencias fueron seleccionadas con los siguientes criterios

- Que sea posible la concreción de los criterios rectores de la metodología de investigación.

- Que sean procesos colectivos vigentes o en realización.

- Que haya diversidad de actores dispuestos al diálogo de saberes, desde dentro y fuera de la experiencia.

- Que existan huellas, memorias, testimonios, que permitan acercarse a la experiencia.

- Que los actores, organizaciones o personas que tradicionalmente aparecen como beneficiarios, se reconozcan como participantes de las experiencias.

En la selección de casos, forma parte de la propuesta metodológica propiciar la diversidad y no la exclusión, y que las experiencias seleccionadas sean diferentes entre sí en los siguientes puntos:

- Pretexto temático

- Contextos regionales

- Formas asociativas

- Intencionalidad

- $\quad$ Sistematización de prácticas

\section{PRIMEROS RESULTADOS}

Si bien este proyecto fue aprobado hace poco tiempo, la Facultad de Periodismo y Comunicación Social está inserta en el territorio desde hace años con prácticas sociocomunicacionales. Desde el mismo momento de la inundación se reconfiguraron esas prácticas a la atención de la crisis y a la resolución de problemáticas derivados de la misma. Esa experiencia sirvió, por un lado, para la formulación del proyecto, y por otro, para la obtención de datos para la construcción de mapas socio-comunicacionales. Así, en los barrios mencionados anteriormente se han identificado y descrito instituciones formales y no formales, políticas públicas implementadas antes, durante y después de la inundación, tales como programas de documentación o de terminalidad educativa primaria y secundaria. Se obtuvieron relatos de referentes sociales y de vecinos, sobre la inundación y sobre representaciones sociales de la pobreza y la vulnerabilidad. Se avanzó, a partir de esto, en la resolución de algunas problemáticas vinculadas a derechos sociales, tales como la regularización dominial. También se avanzó en el mapa de zoonosis, a partir de la identificación en territorio de vectores (por ejemplo, leptopirosis).

Otros resultados replantean, desde la universidad, del modo de darse de los saberes y de las prácticas de coconstrucción de los mismos, que se fueron dando durante y luego de la formulación del proyecto. Podemos resaltar la puesta en diálogo de investigadores de las llamadas ciencias duras con investigadores de las ciencias sociales, lo que reconfiguró, de algún modo, las prácticas de la ciencia de nuestra universidad, a partir del trabajo en red de las distintas unidades académicas, centros de investigación e investigadores. Esto permitió la superación de prejuicios y de fronteras disciplinares, haciendo de la interdisciplinariedad y transdisciplinariedad una práctica integral y necesaria para el abordaje territorial.

Desde el proyecto pueden mencionarse, también como primeros resultados, la puesta en común de concebir al conocimiento y a las prácticas socio-culturales de modo 
holístico, como un todo integral y complejo. ${ }^{6}$ En relación a esto se ha conformado Unidad de Investigación y Transferencia, a fin de generar espacios dialógicos de producción colectiva de conocimientos entre los equipos participantes del proyecto para promover el abordaje integral del territorio y para planificar y gestionar las prácticas en territorio.

\section{PRIMERAS CONCLUSIONES-OBJETIVOS}

En síntesis, ésta investigación se propone aprehender desde la complejidad de las prácticas de cómo ir hacia los otros, respetando las diferencias y con el afán de construir nuevos sentidos que fortalezcan el bien común. Desde la dimensión comunicativa nos proponemos poner causes para recuperar la palabra de todos y todas, facilitando esos procesos de construcción de sentidos y generando nuevos desarrollos humanos y colectivos.

También queremos recuperar lo realizado a partir de registros específicamente diseñados para guardar memorias y por consiguiente recuperar los saberes del proceso que están inscriptos en la memoria de las prácticas.

Desde la sistematización que parte de una mirada compleja sobre las prácticas comunicacionales, buscamos disenar dispositivos previos que nos permitan evaluar constantemente las instancias del camino como una bitácora precisa que guarde los relatos.

Intentamos apreciar nuestras prácticas como una manera de construir región y territorio, conocerlo caminando, al encuentro de los saberes endógenos y exógenos con el claro objetivo de 'aprehender haciendo'.

Vamos hacia una comprensión del territorio como parte de la naturaleza cósmica de ser red, observando sus niveles de participación y expresión que nos permitirán cotejar la escala de multiplicación. Queremos, como dijimos, poner cauces en la escala para ver fluir la acción de 'hacer-ser humano' y 'hacer-ser colectivo'.

Buscamos priorizar la construcción de conocimientos y la producción de contenidos en y desde el lugar, considerando que el territorio está en constante movimiento y conserva la memoria de su ser ancestral en un tiempo mucho más largo que el tiempo antrópico. Del mismo modo, buscamos considerar nuestro espacio de comunicación como un 'lugar en el mundo' donde suceden la construcción de la identidad, el diálogo de la diversidad y la fusión de las culturas.

6 Así, por ejemplo, la salud es concebida como 'salud total', donde salud humana y salud animal no pueden pensarse de modo separado, sino que están profundamente imbricadas entre ellas e insertas en un contexto material y sociocultural
Intentamos, sobre todo, construir un espacio de reflexión y acción donde se promuevan la equidad, la relación y la creación para dar lugar a la producción de sentidos éticos para el cambio social, desde un pensamiento estratégico y un pensamiento complejo que nos permita realizar una visión reflexiva sobre las prácticas para la toma de decisiones.

Entre otros objetivos, resultado de la primera fase de la investigación, están:

- Comprender los sentidos del hacer y la dimensión holística de la realidad.

- Construir un pensamiento crítico frente al discurso dominante.

- Crear las condiciones para recuperar la palabra de las personas y de la comunidad.

- Crear condiciones para que aparezcan los relatos.

- Tener en cuenta los sentimientos, costumbres, hábitos y creencias de los habitantes del territorio.

- Crear condiciones para la autopoiesis (creación de uno mismo) y la autonomía para la producción de nuevas creencias, valores y modos de habitar el territorio.

\section{REFERENCIAS}

Boaventura de Sousa Santos (2005). En Umbrales: "La Universidad del siglo XXI: Para una Reforma democrática y emancipadora de la Universidad". Universidad Autónoma de México, México.

Ceraso, Cecilia y otros (2011). Sembrando mi Tierra de Futuro. Comunicación, planificación y gestión para el desarrollo endógeno. Ediciones EPC de Periodismo y comunicación. La Plata, Argentina.

Cortés, Joaquín, Morguillo, Lucas (2013). Tesis de Licenciatura en Comunicación Social: "Desafíos en una Argentina transformadora: la comunicación en procesos de desarrollo de Gestión Cultural”. Facultad de Periodismo y Comunicación Social, Universidad Nacional de La Plata, La Plata, Argentina.

Díaz Bordenave, J. (1987). ¿Qué es comunicación? Necesidad y reto en América Latina. Carrasquilla Editores. México.

Esteva, Gustavo (1996). Diccionario del Desarrollo. Una guía del Conocimiento como poder. Wolfang Sachs. PRATEC.

Foucault Michel (1992). El Orden del Discurso. Tusquets editores, Buenos Aires.

Foucault, Michel (2000). Los Anormales. Curso en el College de France 1974-1975. Fondo de Cultura Económica, España.

Freire, Paulo (2004). ¿Extensión o Comunicación? Siglo XXI, Buenos Aires, Argentina . 
Giarraca, Norma. (2006). "La tragedia del desarrollo: Disputas por los recursos naturales en la Argentina”. En Revista Sociedad No 26, Facultad de Ciencias Sociales, UBA.

Gutierrez, Francisco y Prado Cruz (2000). Ecopedagogía y ciudadanía Planetaria, ILPEC, Heredia, Costa Rica.

Gutiérrez, Francisco (2000). Seminario de Comunicación y Educación Popular. Maestría PLANGESCO, UNLP, La Plata.

Martín-Barbero, Jesús (1987). De los medios a las mediaciones. Comunicación, cultura y hegemonía. G. Gili, Barcelona.

Mata, María Cristina (1990). Nociones para pensar la comunicación y la cultura masiva. Educación para la comunicación, La Crujia, Buenos Aires.

Melano, María Cristina (2000). "La ilusión del desarrollo y la profesión del Trabajo Social”. En Anuario del Departamento de Servicio Social de la Universidad de Mar del Plata. Facultad de Ciencias de la Salud y Servicio Social. Mar del Plata, Argentina.

Pascuali Antonio (1963). Comunicación y Cultura de masas. Monte Ávila. Caracas.

Prado, Cruz; Gutiérrez, Francisco (1997). Pedagogía para la educación en derechos humanos Módulo II Todos son procesos. Editorial ILPEC, Costa Rica.

Prieto Castillo, Daniel (1995). Mediación de materiales para la comunicación rural. INTA - DICOM, Buenos Aires.

Prieto Castillo, Daniel (1996). Palabras e imágenes para la comunicación impresa. UCLAP, Quito.

Touraine, Alain (2006). Crítica de la Modernidad. Fondo de Cultura Económica, España. 